DOI : https://doi.org/10.24123/jbt.v5i2.4693

\title{
DESAIN LAPORAN KEUANGAN UMKM BERBASIS MICROSOFT EXCEL PADA SUNSHINE LAUNDRY
}

\author{
Andreuw K. Pantow ${ }^{1}$, Ivoletti M. Walukow ${ }^{2}$, Christony Maradesa ${ }^{3}$, Esrie A. N. \\ Limpeleh $^{4}$ \\ ${ }^{1,2,3,4}$ Politeknik Negeri Manado; Manado, Indonesia \\ Email : andreuwkristian@gmail.com ${ }^{1}$
}

\begin{abstract}
This study aims to design the financial statements of Sunshine Laundry using the Microsoft Excel application. The research method was descriptive qualitative. Instruments of data collection was down through interview in the form of questions regarding the recording of financial statements. While the data collection instrument with documentation, was done through namely evidence of transactions that occurred in the business. The results of this study indicate that the design of financial statements with Microsoft Excel helps Sunshine Laundry in compiling financial reports in accordance with EMKM accounting standards. The design of financial reports using Microsoft Excel is assisted by data flow diagrams to describe the flow of the system consisting of a menu design sheet, module 1, module 2, price list, transaction list, account type, chart of account, general journal, income statement, and statement of financial position.
\end{abstract}

Keywords : Design of financial report, Microsoft Excel, accounting standards.

\section{Pendahuluan}

Perkembangan tekonologi yang semakin cepat berdampak pada proses pembuatan laporan keuangan, tetapi pencatatan akuntansi terkomputerisasi masih sulit ditemui pada usaha mikro, kecil, dan menengah (UMKM). Penggunaan teknologi dalam mencatat transaksi bisnis dapat membantu pelaku usaha dalam menjalankan kegiatan operasionalnya. Otomatisasi sistem informasi akuntansi menyederhanakan proses akuntansi, membuatnya lebih cepat dan efisien (Carey, 2015) dan (Xie et al., 2014). Entitas tidak perlu lagi membuat laporan keuangan secara manual untuk mengurangi kesalahan dalam proses pencatatan pada setiap transaksi yang terjadi. Laporan keuangan tahunan yang disajikan oleh perusahaan, akan menunjukkan kondisi keuangan selama periode akuntansi, hasilnya dapat dibandingkan dengan periode akuntansi sebelumnya. Untuk alasan ini, sudah sewajarnya untuk menggunakan akuntansi berbasis teknologi (H. D. Kim et al., 2013) dan (Nicholas, C., \& Fruhmann, 2014).

Dampak kemajuan teknologi pada pembuatan laporan keuangan yaitu munculnya aplikasi-aplikasi akuntansi yang dapat mendukung aktivitas UMKM. Tetapi masih banyak pelaku UMKM yang memiliki permasalahan dalam proses membuat laporan keuangan. Banyak usaha kecil dan menengah tidak melakukan pencatatan keuangan 
dengan benar atau tidak sama sekali dan tidak menyadari perkembangan bisnis mereka (Murtiningtyas, 2013). Aplikasi akuntansi yang didesain begitu rumit, membuat para pelaku usaha sulit untuk menggunakannya, apalagi tidak memiliki pemahaman mengenai akuntansi dan teknologi. Hal tersebut membuat para pelaku usaha tidak memiliki niat untuk menggunakan aplikasi akuntansi. Oleh karena itu, masih banyak UMKM yang menggunakan pencatatan akuntansi secara manual. Entri manual seringkali tidak lengkap dan tidak sesuai dengan Standar Akuntansi Keuangan Mikro, Kecil, dan Menengah (SAK EMKM), yang membuat laporan keuangan tidak disajikan secara lengkap dan andal (Andarsari \& Dura, 2018), (Coram, 2018), dan (Sari, 2013).

Sistem informasi akuntansi yang baik dan mudah digunakan, dibutuhkan oleh pelaku UMKM agar dapat menyajikan pencatatan akuntansi yang tepat sesuai dengan SAK EMKM. Perilaku seseorang saat menggunakan aplikasi didasarkan oleh niat mereka untuk menggunakan perangkat lunak. Pengguna menggunakan aplikasi akuntansi ketika mereka dapat menggunakan komputer dan yakin bahwa perangkat lunak dapat menawarkan manfaat dan kemudahan penggunaan. Technology Acceptance Model (TAM) menjelaskan bahwa, persepsi kemudahan penggunaan adalah faktor penting yang berdampak pada minat pengguna sistem. (Darmaningtyas \& Suardana, 2017), (Aditya \& Wardhana, 2016), (Kurniawati et al., 2017), (Wang, 2002), (Pantow et al., 2021), (Bedard et al., 2003), dan (Rahmawati \& Narsa, 2019), menemukan bahwa konstruk persepsi kemudahan penggunaan merupakan salah satu faktor yang mempengaruhi niat untuk menggunakan suatu sistem atau aplikasi.

Microsoft Excel adalah aplikasi perangkat lunak yang bermanfaat untuk mempermudah dalam membuat laporan keuangan. Aplikasi ini dapat menerapkan fungsi akuntansi dengan cepat dan efisien, sehingga mudah untuk dioperasikan oleh penggunanya. Perangkat lunak Microsoft Excel lebih murah operasionalnya dibandingkan dengan aplikasi akuntansi lainnya seperti Accurate, Zahir, dan Myob. Akan tetapi, meskipun memiliki biaya yang murah, diperlukan adanya pemograman secara manual dengan menggunakan fungsi excel untuk menghasilkan suatu aplikasi akuntansi yang terotomatisasi. Membuat rumus secara manual dapat menghasilkan aplikasi akuntansi yang sesuai dengan kebutuhan dan karakteristik aktivitas bisnis dan kemampuan pelaku UMKM dalam menjalankan aplikasi tersebut (S. H. Kim et al., 2017) dan (Daspit \& D’Souza, 2017).

Sunshine Laundry merupakan usaha yang bergerak bidang jasa pencucian pakaian yang diperlukan oleh konsumen. Usaha didirikan tahun 2013 dan beralamat di Jalan Raya Politeknik, Kairagi Dua. Laporan keuangan Sunshine Laundry masih dibukukan secara manual dan proses penyusunan laporan keuangan tidak sesuai dengan standar akuntansi UMKM. Oleh sebab itu, dalam menerapkan suatu sistem akuntansi yang sempurna dan sinkron dengan kebutuhan pelaku usaha, maka peneliti dan pelaku usaha perlu menyelesaikan permasalahan dengan mendesain suatu aplikasi akuntansi dengan menggunakan aplikasi Microsoft Excel.

Berdasarkan permasalahan yang digambarkan di atas, penelitian ini bertujuan untuk merancang model laporan keuangan Sunshine Laundry dengan menggunakan aplikasi Microsoft Excel. 


\section{Kerangka Teori}

\section{Standar Akuntansi Entitas Mikro Kecil dan Menengah}

\section{Ruang Lingkup Standar Akuntansi Entitas Mikro Kecil dan Menengah}

Standar Akuntansi Keuangan (SAK) Entitas mikro, kecil, dan menengah (EMKM) ditujukan untuk dipakai oleh usaha mikro, kecil, dan menengah. UKM adalah perusahaan yang bukan memiliki akuntabilitas publik yang signifikan, sesuai dengan Standar Akuntansi Keuangan Entitas Tanpa Akuntabilitas Publik (SAK ETAP), yang memenuhi definisi dan kriteria usaha mikro, kecil, dan menengah sebagaimana diatur dalam peraturan perundang-undangan yang berlaku di Indonesia, untuk setidaknya dua tahun berturut-turut (Hasan \& Gusnardi, 2018).

\section{Tujuan Laporan Keuangan}

Tujuan laporan keuangan tahunan adalah untuk memberikan informasi tentang kekayaan bersih perusahaan, posisi keuangan dan hasil operasi yang akan membantu sejumlah besar pengguna untuk membuat keputusan ekonomi dan memperoleh informasi bagi mereka yang tidak mempunyai laporan keuangan tertentu. Pengguna ini termasuk penyedia sumber daya untuk perusahaan seperti kreditur dan investor. Untuk mencapai tujuan tersebut, laporan keuangan juga menunjukkan akuntabilitas manajemen atas sumber daya yang dipercayakan (Hasan \& Gusnardi, 2018).

\section{Laporan Posisi Keuangan}

Informasi posisi keuangan perusahaan berupa informasi aset, liabilitas, dan ekuitas perusahaan suatu periode, dan tersaji pada laporan posisi keuangan (Hasan \& Gusnardi, 2018). Elemen-elemen ini didefinisikan sebagai:

a. Aset yaitu harta yang dikelola perusahaan karena kejadian masa lalu dan kemungkinan akan menerima manfaat finansial di masa depan.

b. Liabilitas adalah kewajiban perusahaan saat ini dari peristiwa masa lalu, dan pemenuhannya menyebabkan arus keluar dari sumber daya dan manfaat ekonomi dari perusahaan.

c. Ekuitas adalah sisa kekayaan perusahaan setelah dikurangi semua kewajibannya.

\section{Laporan Laba Rugi}

Pada bagian ini, perusahaan harus memberikan laporan laba rugi yang menunjukkan kinerja keuangan perusahaan selama periode waktu tertentu. Bagian ini juga mengatur laporan laba rugi dan informasi tampilannya. Laporan laba rugi perusahan dapat mencakup akun-akun berikut: a) pendapatan; b) beban keuangan; c) beban pajak; jika penyajian tersebut berkaitan dengan pemahaman atas kinerja keuangan perusahaan, maka perusahaan harus menyajikan laporan keuangan dan bagian-bagian laporan keuangan. Laporan laba rugi mencakup semua pendapatan dan beban yang dicatat selama periode tersebut, kecuali disyaratkan lain oleh SAK EMKM. SAK EMKM mengatur tentang penanganan koreksi kesalahan dan dampak perubahan metode akuntansi dan penilaian. Hal ini disajikan sebagai penyesuaian retroaktif untuk periode sebelumnya dan tidak mempengaruhi pendapatan dalam periode perubahan (Hasan \& Gusnardi, 2018).

\section{Catatan atas Laporan Keuangan}

Catatan atas laporan keuangan tahunan meliputi :

a. Pernyataan bahwa laporan keuangan tahunan telah memenuhi SAK EMKM.

b. Ikhtisar kebijakan akuntansi.

c. Tambahan informasi dan detail akun tertentu yang menggambarkan transaksi penting dan material untuk membantu pengguna memahami laporan keuangan. 
Jenis informasi tambahan yang disajikan tergantung pada jenis bisnis yang dijalankan perusahaan.

Catatan atas laporan keuangan disusun secara sesistematis mungkin. Setiap akun dalam laporan keuangan dikaitkan dengan informasi yang relevan dalam catatan atas laporan keuangan (Hasan \& Gusnardi, 2018).

\section{Microsoft Excel}

Microsoft Excel merupakan program perhitungan yang sangat terkenal di Indonesia. Banyak pemakai Microsoft Excel yang hanya memakai program ini buat memasukan data di tabel, tetapi Microsoft Excel memiliki banyak pilihan untuk membuat laporan tabel dan menyelesaikan banyak perhitungan yang rumit. Excel menawarkan beberapa beberapa solusi pemecahan masalah, tergantung pada kondisi yang berlaku. Jenis masalah di Microsoft Excel ini dapat diselesaikan dengan menggunakan fungsi logika (Wicaksono et al., 2008).

\section{Metode Penelitian}

Jenis penelitian ini adalah penelitian kualitatif deskriptif yang bertujuan untuk menjelaskan karakteristik subjek yang diteliti, menyelediki berbagai aspek dari fenomena tertentu, dan memberikan ide-ide untuk masalah yang akan diuji atau diselidiki (Indriantoro \& Supomo, 2016). Penelitian ini menggunakan pendekatan deskriptif untuk memberikan solusi terhadap kebutuhan usaha mikro, kecil, dan menengah atas sistem aplikasi akuntansi dalam pengelolaan keuangan.

Sumber data dalam penelitian ini terdiri dari dua sumber data, yaitu :Data primer adalah sumber data penelitian yang diambil langsung dari sumber aslinya (tidak melalui media perantara), peneliti mengumpulkan data utama secara terarah, sehingga dapat memberikan jawaban atas pertanyaan penelitian (Indriantoro \& Supomo, 2016). Data primer dalam penelitian ini diperoleh melalui wawancara tatap muka dengan pemilik usaha. Kedua, data sekunder adalah data penelitian yang diterima peneliti secara tidak langsung melalui media perantara (Indriantoro \& Supomo, 2016). Data sekunder dalam penelitian ini berupa bukti transaksi, catatan laporan keuangan yang tersusun dalam arsip.

Teknik pengumpulan data yang dipakai pada penelitian ini berupa wawancara dan dokumentasi. Instrumen pengumpulan data melalui wawancara terkait beberapa pertanyaan mengenai pencatatan laporan keuangan. Sedangkan instrumen pengumpulan data dengan dokumentasi berupa bukti-bukti transaksi yang terjadi pada usaha tersebut.Teknik analisis data dalam penelitian ini, yaitu :Mengumpulkan data dan informasi yang diperlukan untuk memperoleh gambaran kegiatan usaha melalui wawancara, dokumentasi, dan observasi langsung di lapangan.Lalu,mengidenfikasi masalah yang ada dengan melakukan analisis terhadap kebutuhan sistem aplikasi akuntansi yang akan dirancang, serta pengendalian yang dibutuhkan. Akhirnya, merancang sistem aplikasi akuntansi dengan menggunakan perangkat lunak Microsoft Excel 2013, dan mempertimbangkan kebutuhan sistem aplikasi akuntansi yang diperlukan pada usaha tersebut.

\section{Hasil dan Pembahasan \\ Pencatatan Keuangan Pada Sunshine Laundry}

Informasi yang dibutuhkan untuk mengetahui perkembangan usaha adalah dengan melihat pencatatan akuntansi apakah sesuai dengan standar akuntansi UMKM. Pencatatan keuangan pada Sunshine Laundry masih dilakukan secara manual dan belum menerapkan 
pencatatan sesuai dengan standar akuntansi UMKM. Berdasarkan hasil wawancara dengan pemilik usaha, aplikasi akuntansi pernah diterapkan oleh pemilik dalam proses penyusunan laporan keuangan. Akan tetapi, keterbatasan pemilik usaha yang tidak memiliki pengetahuan dalam bidang teknologi dan akuntansi menyebabkan penggunaan aplikasi akuntansi tidak ada keberlanjutan hingga saat ini. Berdasarkan SAK EMKM, laporan keuangan seharusnya terdiri dari laporan laba rugi, laporan posisi keuangan, dan catatan atas laporan keuangan.

Proses pencatatan keuangan secara manual pada Sunshine Laundry dilakukan dengan mencatat setiap transaksi pemasukkan atau pengeluaran pada kolom keterangan. Pencatatan tersebut tidak sesuai dengan mekanisme pencatatan akuntansi, yang seharusnya memperhatikan keseimbangan atau hubungan antara kolom debit dan kredit.

\section{Desain Laporan Keuangan Dengan Microsoft Excel}

Berdasarkan sistem pencatatan keuangan pada Sunshine Laundry, maka dibuat desain sistem akuntansi menggunakan Microsoft Excel untuk menyelesaikan permasalahan pencatatan keuangan pada usaha Sunshine Laundry. Sistem akuntansi yang baik membantu pengelolaan keuangan pada usaha tersebut, sehingga pemilik dapat mengetahui perkembangan usahanya. Aliran data dan proses untuk mengelola data ke dalam sistem akuntansi dibuat dalam bagan alir (data flow diagram). Bagan alir yang baik dan jelas merupakan bagian yang penting dalam perancangan sistem informasi yang kompleks dan pengembangan program komputer (Mulyadi, 2016). Arah panah dari aliran data menunjukkan aliran data masukan (input) dan data keluaran (output) ke dalam sistem aplikasi akuntansi yang dirancang dengan menggunakan Microsoft Excel. Berikut gambar 1 Data Flow Diagram (DFD) sistem informasi akuntansi yang dirancang oleh penulis untuk diterapkan pada Sunshine Laundry. 


\section{Diagram Context}

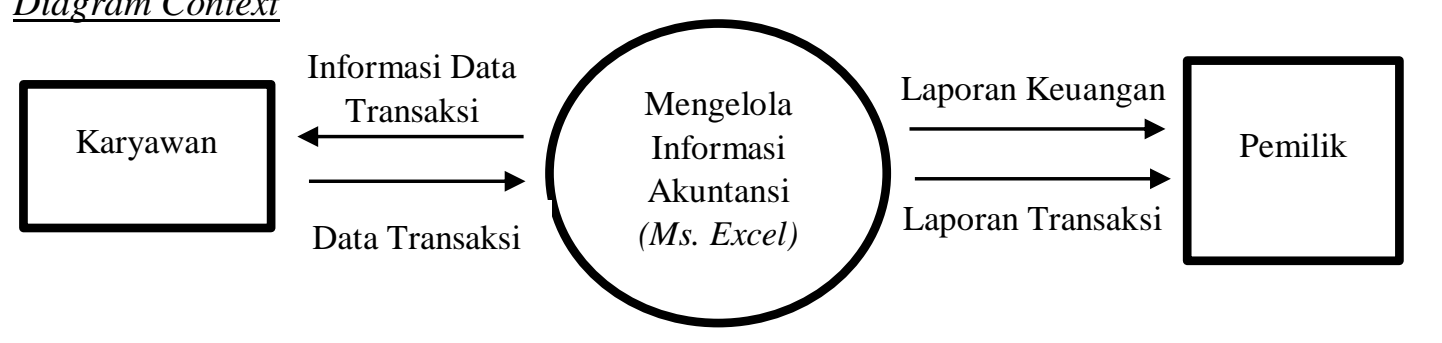

\section{Diagram Level 0}

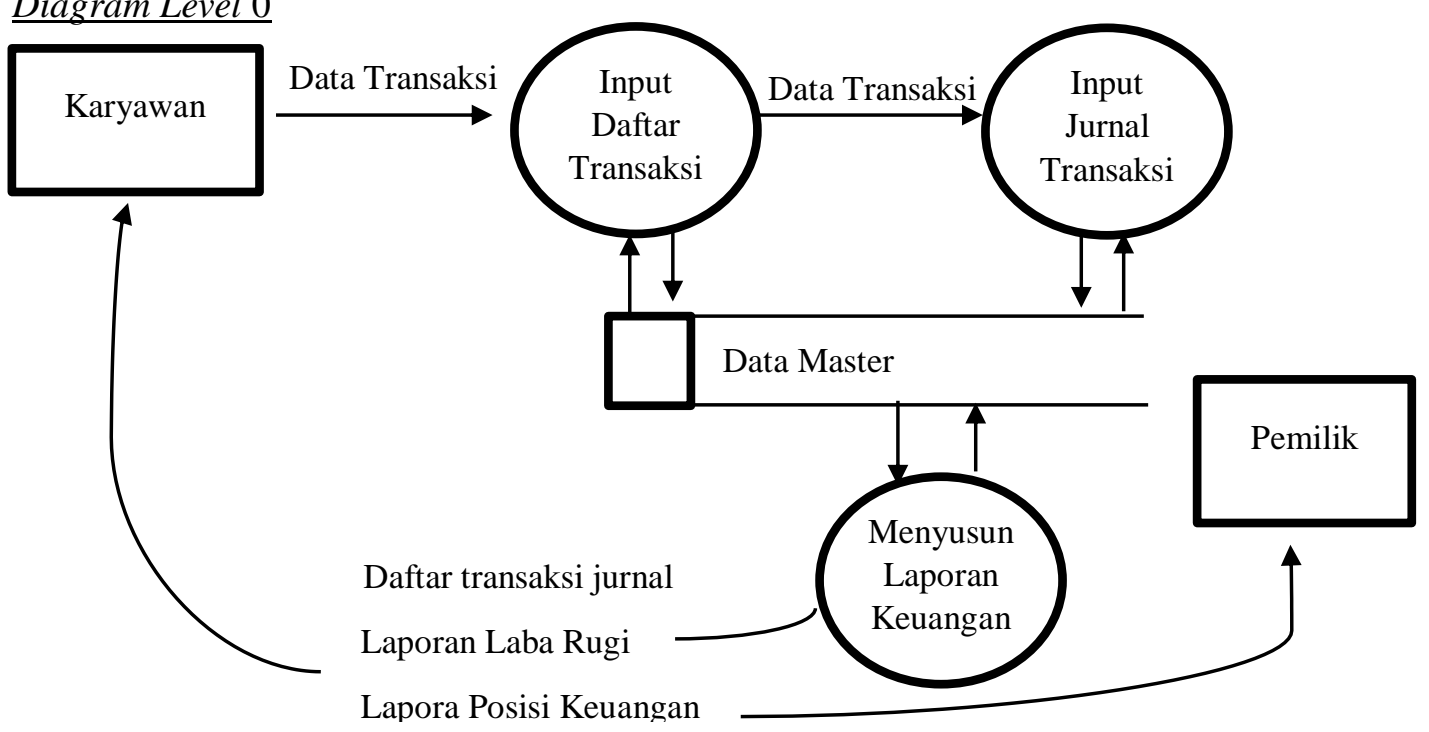

Gambar 1. DFD sistem informasi akuntansi Sunshine Laundry

Sumber : Data Diolah (2021)

\section{Perancangan Menu}

Perancangan menu digunakan sebagai tampilan awal aplikasi akuntansi berbasis microsof excel. Menu dibuat dengan tujuan untuk mempermudah akses data yang diperlukan. Tampilan menu dapat dilihat pada gambar 2 berikut.

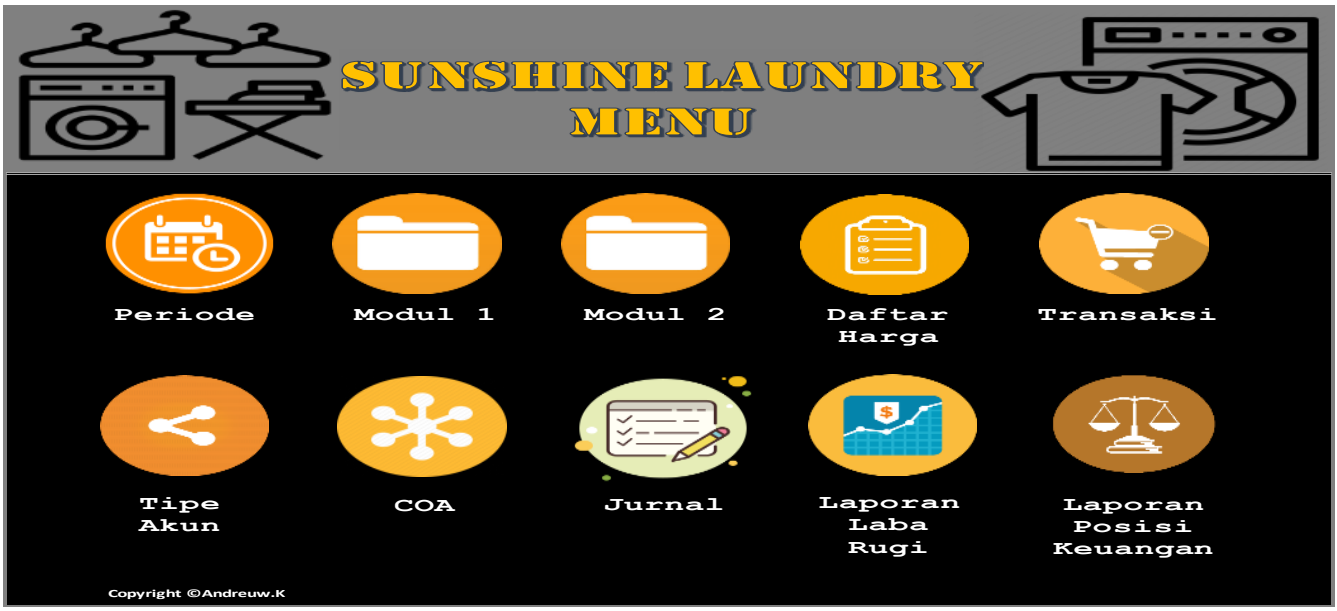

Gambar 2. Tampilan Menu 


\section{Perancangan Modul 1 (Daftar Kas dan Bank)}

Perancangan modul 1 yang memuat daftar kas dan bank bertujuan untuk memberikan informasi perubahan saldo kas dan bank. Modul 1 terdiri dari kolom kode kas dan bank, nama kas dan bank, saldo awal kas dan bank, penambahan dan pengurangan saldo, serta saldo akhir kas dan bank. Tampilan modul 1 disajikan pada gambar 3 berikut.

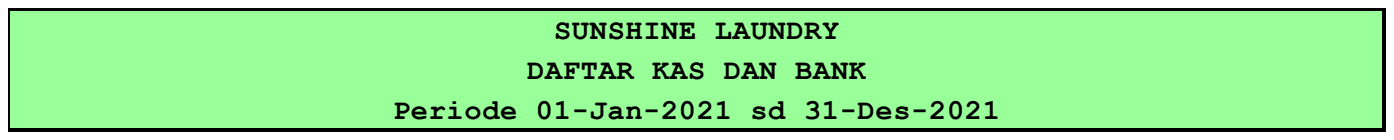

\begin{tabular}{|c|c|c|c|c|c|}
\hline Kode & Nama Kas dan Bank & Saldo Awal & Penambahan & Pengurangan & Saldo Kas Akhir \\
\hline K1 & Kas Umum & 1.500 .000 & - & - & 1.500 .000 \\
\hline K2 & Kas Kecil & 500.000 & - & - & 500.000 \\
\hline B1 & Bank BRI & 10.000 .000 & - & - & 10.000 .000 \\
\hline \multirow[t]{9}{*}{ B2 } & Bank BNI & 5.000 .000 & - & - & 5.000 .000 \\
\hline & & & - & - & - \\
\hline & & & - & - & - \\
\hline & & & - & - & - \\
\hline & & & - & - & - \\
\hline & & & - & - & - \\
\hline & & & - & - & - \\
\hline & & & - & - & - \\
\hline & & & - & - & - \\
\hline TOTAL & KAS \& BANK & 17.000 .000 & - & - & 17.000 .000 \\
\hline
\end{tabular}

Gambar 3. Tampilan Modul 1 (Daftar Kas dan Bank)

Rancangan modul 1 dibuat dengan langkah-langkah sebagai berikut :

1. Membuat perikop nama usaha, daftar kas dan bank, serta periode transaksi.

2. Membuat kolom kode kas atau bank dan kolom saldo awal, kolom ini dibuat secara manual tanpa menggunakan fungsi excel.

3. Membuat kolom penambahan, fungsi excel yang digunakan pada bagian ini akan dimasukan setelah membuat sheet transaksi. Setelah sheet transaksi dibuat, maka fungsi yang perlu dimasukkan dalam kolom penambahan adalah =SUMIF(TRX_FILTER3;1\&"-"\&B7\&"PEMASUKAN";TRX_JUMLAH).

4. Membuat kolom pengurangan, fungsi excel yang digunakan pada bagian ini akan dimasukkan setelah membuat sheet transaksi. Setelah sheet transaksi dibuat, maka fungsi yang perlu dimasukkan dalam kolom pengurangan adalah =SUMIF(TRX_FILTER3;1\&"-"\&B7\&"PENGELUARAN";TRX_JUMLAH).

5. Membuat kolom saldo kas akhir, kolom ini dibuat dengan cara menjumlahkan kolom saldo awal, kolom penambahan, dan mengurangkan dengan kolom pengurangan.

\section{Perancangan Modul 2 (Daftar Pemasukan dan Pengeluaran)}

Perancangan modul 2 yang memuat daftar pemasukan dan pengeluaran bertujuan untuk memberikan informasi perubahan saldo pemasukan dan pengeluaran kas. Modul 2 terdiri dari kolom kode pemasukan dan pengeluaran, keterangan, jenis, dan total. Tampilan modul 2 disajikan pada gambar 4 berikut. 


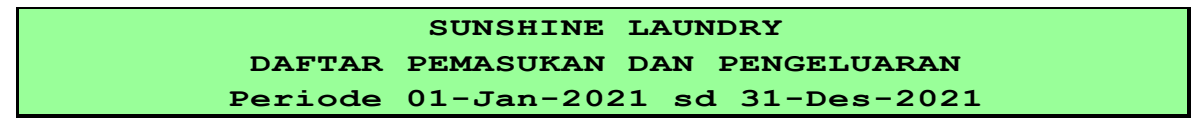

\begin{tabular}{|c|l|l|c|}
\hline Kode & \multicolumn{1}{|c|}{ Keterangan } & \multicolumn{1}{|c|}{ Jenis } & Total \\
\hline P-01 & Pendapatan Jasa Laundry & Pemasukan & 21.000 \\
\hline P-02 & Pendapatan Lain-Lain & Pemasukan & - \\
\hline B-01 & Beban Gaji & Pengeluaran & - \\
\hline B-02 & Beban Listrik & Pengeluaran & - \\
\hline B-03 & Beban ATK & Pengeluaran & 15.000 \\
\hline B-04 & Beban Deterjen \& Pewangi & Pengeluaran & - \\
\hline B-05 & Beban Pembungkus Pakaian & Pengeluaran & - \\
\hline & & & - \\
\hline
\end{tabular}

Gambar 4. Tampilan Modul 2 (Daftar Pemasukan dan Pengeluaran) Sumber : Data Diolah (2021)

Rancangan modul 2 dibuat dengan langkah-langkah sebagai berikut :

1. Membuat perikop nama usaha, daftar pemasukan dan pengeluaran, dan periode transaksi.

2. Membuat kolom kode, keterangan, kolom ini dibuat secara manual tanpa menggunakan fungsi excel.

3. Membuat kolom jenis pemasukan dan pengeluaran, kolom ini dibuat dengan alur sebagai berikut, memilih menu data, data validation, settings, pada kolom allow pilih list, dan untuk kolom source input Pemasukan;Pengeluaran, selanjutnya pilih ok.

4. Membuat kolom total, fungsi excel pada bagian ini akan dimasukkan setelah membuat sheet daftar transaksi. Setelah sheet daftar transaksi dibuat, maka fungsi yang dibuat dalam kolom total adalah =SUMIF(TRX_FILTER4;1\&""\&B7;TRX_JUMLAH).

\section{Perancangan Daftar Harga}

Perancangan daftar harga bertujuan untuk memberikan informasi mengenai harga jasa laundry yang ditawarkan kepada konsumen. Sheet daftar harga terdiri dari kolom kode jasa, keterangan, dan harga/kg. Tampilan sheet daftar harga disajikan pada gambar 5 berikut.

DAFTAR HARGA

\begin{tabular}{|c|l|r|}
\hline Kode Jasa & Keterangan & Harga / (Kg, Set, Buah, M2) \\
\hline CS & Cuci-Setrika & 7.000 \\
\hline S & Setrika & 5.000 \\
\hline SB-Set & Seprei Besar-Set & 5.000 \\
\hline SK-Set & Seprei Kecil-Set & 15.000 \\
\hline SB-Bh & Seprei Besar-Bh & 12.500 \\
\hline Sk-Bh & Seprei Kecil-Bh & 10.000 \\
\hline SLK-Bh & Selimut Kecil-Bh & 8.000 \\
\hline SLS-Bh & Selimut Sedang-Bh & 8.000 \\
\hline SLB-Bh & Selimut Besar-Bh & 10.000 \\
\hline BCB-Bh & Bed Cover Besar-Bh & 15.000 \\
\hline BCK-Bh & Bed Cover Kecil-Bh & 40.000 \\
\hline J & Jas (Hanger + Plastik) & 30.000 \\
\hline JC & Jas+Celana (Hanger Plastik) & 25.000 \\
\hline D & Dress (Hanger + Plastik) & 30.000 \\
\hline B & Boneka & 15.000 \\
\hline K & Karpet & 10.000 \\
\hline SB & Springbed & 15.000 \\
\hline SF & Sofa & 360.000 \\
\hline
\end{tabular}

Gambar 5. Tampilan Sheet Daftar Harga

Sumber : Data Diolah (2021) 
Rancangan sheet daftar harga dibuat secara manual tanpa menggunakan fungsi excel. Harga berdasarkan per $\mathrm{kg}$, set, buah, $\mathrm{m}^{2}$, kolom kode jasa disesuaikan dengan keterangan jasa yang ditawarkan kepada konsumen. Sheet daftar harga akan digunakan sebagai informasi pada sheet daftar transaksi untuk mempermudah dalam menginput transaksi.

\section{Perancangan Daftar Transaksi}

Perancangan daftar transaksi bertujuan untuk memasukkan transaksi pemasukan dan pengeluaran yang terjadi selama proses kegiatan usaha. Tabel daftar transaksi terbagi menjadi 2 bagian, tabel utama terdiri dari kolom tanggal transaksi, no bukti, keterangan, kode kas bank, nama kas dan bank, kode pemasukan dan pengeluaran, nama pemasukan dan pengeluaran, dan jumlah. Sedangkan tabel bantu hitung terdiri dari kolom kg, kode jasa, harga $/ \mathrm{kg}$, dan total. Tampilan sheet daftar transaksi disajikan pada gambar 6 berikut.

SUNSHINE LAUNDRY

DAFTAR TRANSAKSI

Periode 01-Jan-2021 sd 31-Des-2021

\begin{tabular}{|c|l|l|l|l|l|l|l|}
\hline Tanggal & No Bukti & Keterangan & Kode 1 & Kas/Bank & Kode 2 & Masuk/Keluar & Jumlah \\
\hline 01/01/2021 & nota-01 & pemasukan & K1 & Kas Umum & P-01 & Pendapatan Jasa Laundry & 21.000 \\
\hline $01 / 02 / 2019$ & nota-02 & pemasukan & K1 & Kas Umum & P-01 & Pendapatan Jasa Laundry & 40.000 \\
\hline $01 / 02 / 2021$ & nota-03 & pengeluaran & K2 & Kas Kecil & B-03 & Beban ATK & 15.000 \\
\hline & & & & & & & \\
\hline & & & & & & & \\
\hline
\end{tabular}

Sumber : Data Diolah (2021)

Gambar 6. Tampilan Sheet Daftar Transaksi

Rancangan sheet daftar transaksi dibuat dengan langkah-langkah sebagai berikut :

1. Membuat perikop nama usaha, daftar transaksi, dan periode transaksi.

2. Membuat kolom tanggal, nomor bukti, keterangan.

3. Membuat kolom kode 1, kolom ini berfungsi sebagai kode bantu untuk kas atau bank. Kolom ini dibuat dengan alur sebagai berikut, memilih menu data, data validation, settings, pada kolom allow pilih list, dan untuk kolom source masukan kode pada modul 1 , selanjutnya pilih ok.

4. Membuat kolom kas/bank, fungsi excel yang dibuat dalam kolom ini adalah =IFERROR(VLOOKUP(E8;'MODUL 1'!B6:G19;2;0);"').

5. Membuat kolom kode 2, kolom ini berfungsi sebagai kode bantu untuk kolom masuk/keluar. Kolom ini dibuat dengan alur sebagai berikut, memilih menu data, data validation, settings, pada kolom allow pilih list, dan untuk kolom source masukan kode pada modul 2, selanjutnya pilih ok.

6. Membuat kolom masuk/keluar, fungsi excel yang dibuat dalam kolom ini adalah =IFERROR(VLOOKUP(G8;'MODUL 2'!B:E;2;0);"').

7. Kolom jumlah dibuat secara manual dengan memasukkan jumlah transaksi pengeluaran atau pemasukan.

\section{Perancangan Tipe Akun}

Perancangan tipe akun dilakukan dengan menggolongkan akun berdasarkan saldo normal dan posisi akun yang nantinya disajikan pada laporan posisi keuangan atau laba 
rugi. Tujuan dibuatnya tipe akun untuk membantu proses penyusunan daftar akun atau Chart of Account (COA). Sheet tipe akun terdiri dari kolom tipe akun, saldo normal, dan posisi. Sheet tipe akun dibuat secara manual, Kolom tipe akun memuat akun-akun yang digunakan dalam transaksi, kolom saldo normal memuat saldo debet atau kredit, dan kolom posisi memuat posisi akun yang akan disajikan pada neraca atau laba rugi. Tampilan sheet tipe akun disajikan pada gambar 7 berikut.

\begin{tabular}{|c|c|c|}
\hline Type Akun & SN & POS \\
\hline Kas & $\mathrm{D}$ & $\mathrm{NRC}$ \\
\hline Piutang & $\mathrm{D}$ & $\mathrm{NRC}$ \\
\hline Aset Lancar Lainnya & $\mathrm{D}$ & NRC \\
\hline Aset Tetap & $\mathrm{D}$ & NRC \\
\hline Akumulasi Penyusutan Aset Tetap & K & NRC \\
\hline Utang Usaha & K & NRC \\
\hline Utang Lancar Lainnya & K & NRC \\
\hline Utang Bank & K & NRC \\
\hline Utang Jangka Panjang Lainnya & K & $\mathrm{NRC}$ \\
\hline Modal & K & NRC \\
\hline Prive & $\mathrm{D}$ & NRC \\
\hline Pendapatan & K & LR \\
\hline Beban & $\mathrm{D}$ & LR \\
\hline Pendapatan Lainnya & K & LR \\
\hline Beban Lainnya & $\mathrm{D}$ & LR \\
\hline
\end{tabular}

Gambar 7. Tampilan Sheet Tipe Akun

Sumber : Data Diolah (2021)

\section{Perancangan Chart of Account (COA)}

Perancangan Chart of Account bertujuan untuk menggolongkan data berdasarkan transaksi yang sejenis yang akan menjadi dasar dalam penyusunan laporan keuangan. Sheet daftar akun (COA) terdiri dari kolom kode akun, keterangan, tipe akun, debet, dan kredit. Tampilan sheet daftar akun disajikan pada gambar 8 berikut.

DAFTAR AKUN

\begin{tabular}{|c|c|c|c|c|}
\hline Kode & Keterangan & Type & Debet & Kredit \\
\hline 1101 & Kas & Kas & 50.000 .000 & \\
\hline 1102 & Piutang & Piutang & 9.000 .000 & \\
\hline 1103 & Perlengkapan 1 (Deterjen \& Pewangi) & Aset Lancar Lainnya & 3.500 .000 & \\
\hline 1104 & Perlengkapan 2 (Pembungkus Pakaian) & Aset Lancar Lainnya & 2.000 .000 & \\
\hline 1201 & Setrika & Aset Tetap & 11.000 .000 & \\
\hline 1202 & Akumulasi Penyusutan Setrika & Akumulasi Penyusutan Aset Tetap & & 2.000 .000 \\
\hline 1203 & Mesin Cuci 1 & Aset Tetap & 12.500 .000 & \\
\hline 1204 & Akumulasi Penyusutan Mesin Cuci 1 & Akumulasi Penyusutan Aset Tetap & & 2.000 .000 \\
\hline 1205 & Mesin Cuci 2 & Aset Tetap & 20.000 .000 & \\
\hline 1206 & Akumulasi Penyusutan Mesin Cuci 2 & Akumulasi Penyusutan Aset Tetap & & 2.000 .000 \\
\hline 1207 & Mesin Cuci 3 & Aset Tetap & 20.000 .000 & \\
\hline 1208 & Akumulasi Penyusutan Mesin Cuci 3 & Akumulasi Penyusutan Aset Tetap & & 2.000 .000 \\
\hline 2101 & Utang Usaha & Utang Usaha & & 11.130 .000 \\
\hline 2201 & Utang Bank & Utang Bank & & 50.000 .000 \\
\hline 3101 & Modal & Modal & & 58.870 .000 \\
\hline 3102 & Prive & Prive & & \\
\hline 3103 & Laba Berjalan & Modal & & \\
\hline 4101 & Pendapatan Jasa & Pendapatan & & \\
\hline 5101 & Beban Gaji Karyawan & Beban & & \\
\hline 5102 & Beban Listrik & Beban & & \\
\hline 5103 & Beban Telepon & Beban & & \\
\hline 5104 & Beban Perlengkapan & Beban & & \\
\hline 5105 & Beban Lain-Lain & Beban & & \\
\hline & & Total & 128.000 .000 & 128.000 .000 \\
\hline
\end{tabular}

Gambar 8. Tampilan Sheet Daftar Akun (COA)

Sumber : Data Diolah (2021) 
Sheet daftar akun dibuat secara manual, terdiri dari kolom kode akun yang memuat kode dari masing-masing akun yang akan digunakan, kolom keterangan yang terdiri dari nama-nama akun, serta kolom debet dan kredit yang memuat saldo awal setiap akun. Untuk kolom tipe akun yang dibuat dengan menggunakan data validation yang dihubungkan dengan sheet tipe akun.

\section{Perancangan Jurnal Umum}

Perancangan jurnal bertujuan untuk memasukan transaksi yang terjadi sesuai dengan tanggal dan kelompok akun pada kolom debet dan kredit. Sheet jurnal terdiri dari kolom tanggal, referensi, keterangan, kode akun, nama akun, debet, dan kredit. Tampilan sheet jurnal disajikan pada gambar 9 berikut.

JURNAL UMUM

\begin{tabular}{|c|c|c|c|c|c|c|}
\hline Tanggal & Ref & Keterangan & Kode & Nama Akun & Debet & Kredit \\
\hline $01 / 01 / 2021$ & & bayar listrik & 5102 & Beban Listrik & 300.000 & \\
\hline $01 / 01 / 2021$ & & bayar listrik & 1101 & Kas & & 300.000 \\
\hline $10 / 01 / 2021$ & & pendapatan jasa & 1101 & Kas & 2.000 .000 & \\
\hline $10 / 01 / 2021$ & & pendapatan jasa & 4101 & Pendapatan Jasa & & 2.000 .000 \\
\hline $14 / 01 / 2021$ & & bayar utang usaha & 2101 & Utang Usaha & 200.000 & \\
\hline $14 / 01 / 2021$ & & bayar utang usaha & 1101 & Kas & & 200.000 \\
\hline $20 / 01 / 2021$ & & pendapatan jasa & 1101 & Kas & 2.500 .000 & \\
\hline $20 / 01 / 2021$ & & pendapatan jasa & 4101 & Pendapatan Jasa & & 2.500 .000 \\
\hline & & & & & & \\
\hline & & & & & & \\
\hline & & & & & & \\
\hline
\end{tabular}

Gambar 9. Tampilan Sheet Jurnal

Sumber : Data Diolah (2021)

Rancangan sheet jurnal umum dibuat dengan langkah-langkah sebagai berikut :

1. Kolom tanggal, ref, keterangan, kode, debet, dan kredit dibuat secara manual tanpa menggunakan fungsi excel.

2. Kolom nama akun dibuat dengan menggunakan fungsi =IF(E5="'";"';VLOOKUP(E5;COA!B:F;2;0)).

3. Kolom kode diberi nama JU_kode, kolom debet diberi nama JU_debet, dan kolom kredit diberi nama JU_kredit. Tujuan dari penamaan ini digunakan untuk mempermudah dalam membuat sheet laba rugi dan laporan posisi keuangan.

\section{Perancangan Laba Rugi}

Perancangan laba rugi bertujuan untuk memberikan informasi bagi pemilik usaha mengenai pendapatan dan beban-beban yang terjadi selama periode berjalan. Pada sheet laba rugi pemilik usaha dapat mengetahui apakah usaha yang dijalankan mengalami keuntungan atau kerugian. Sheet laba rugi terdiri dari kolom kode akun, keterangan, form jurnal, dan jumlah. Tampilan sheet laba rugi disajikan pada gambar 10 berikut. 


\section{LABA RUGI}

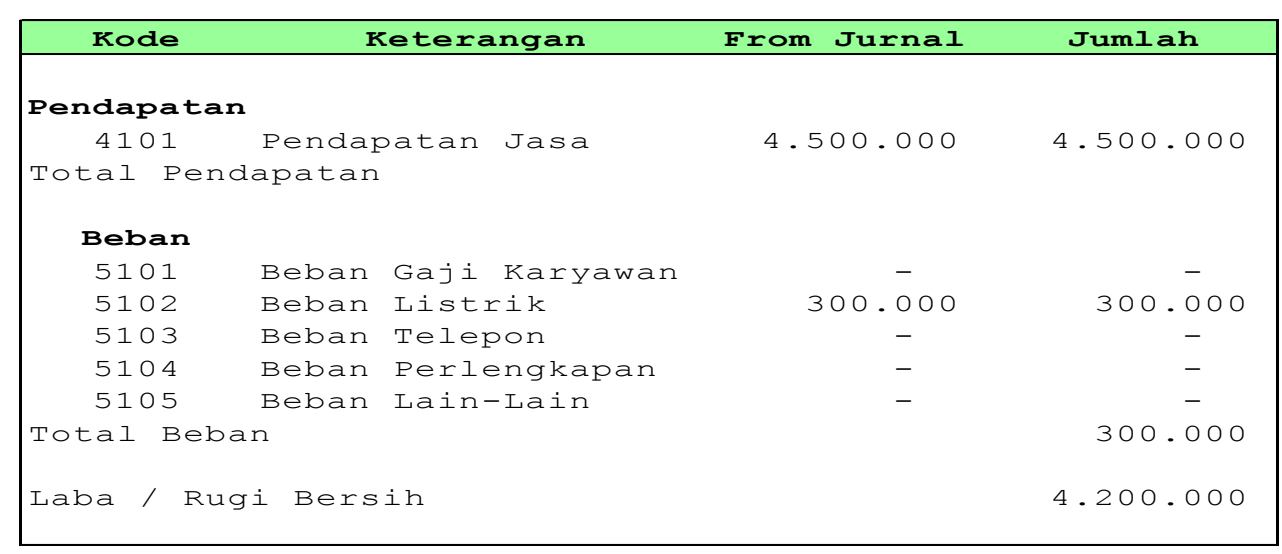

Sumber : Data Diolah (2021)

Gambar 10. Tampilan Sheet Laba Rugi

Rancangan sheet laba rugi dibuat dengan langkah-langkah sebagai berikut :

1. Kolom kode dibuat dengan mengambil kode akun yang ada pada sheet $C O A$ atau daftar akun, yaitu dengan cara =COA!B22.

2. Kolom keterangan dibuat dengan menggunakan fungsi $=$ VLOOKUP(B7;COA!B:F;2;0).

3. Kolom from jurnal berfungsi untuk mengambil nominal transaksi debet atau kredit yang ada pada jurnal umum. From jurnal dibuat dengan menggunakan fungsi $=$ SUMIF(JU_KODE;B7;JU_KREDIT)-SUMIF(JU_KODE;B7;JU_DEBET).

4. Kolom jumlah berfungsi untuk melihat jumlah pendapatan atau beban yang dihasilkan usaha dalam menjalankan bisnisnya, dibuat dengan menggunakan fungsi $=\mathrm{IF}(\mathrm{I} 7=" \mathrm{~K} "$;H7+D7-G7;G7+D7-H7).

\section{Perancangan Laporan Posisi Keuangan}

Perancangan laporan posisi keuangan bertujuan untuk memberikan informasi mengenai posisi aset, kewajiban, dan modal. Bagian ini merupakan hal yang penting bagi pemilik usaha untuk melihat perkembangan usaha kedepannya. Tampilan sheet laporan posisi keuangan disajikan pada gambar 11 berikut. 


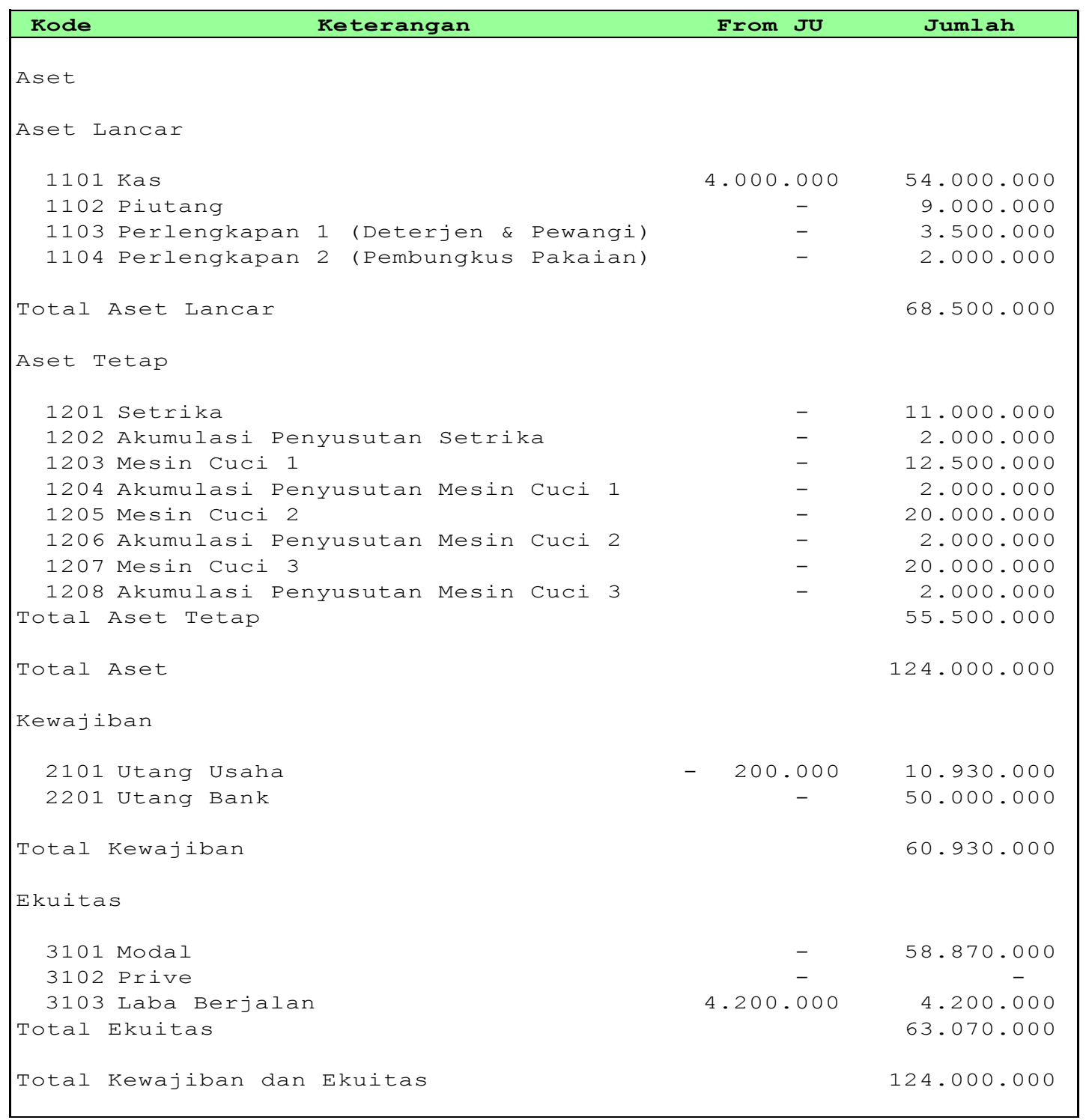

Gambar 11. Tampilan Sheet Laporan Posisi Keuangan

Sumber : Data Diolah (2021)

Rancangan sheet laba rugi dibuat dengan langkah-langkah sebagai berikut :

1. Kolom kode dibuat dengan mengambil kode akun yang ada pada sheet COA atau daftar akun, yaitu dengan cara =COA!B5.

2. Kolom keterangan dibuat dengan menggunakan fungsi $=$ VLOOKUP(B10;COA!B:F;2;0).

3. Kolom from jurnal berfungsi untuk mengambil nominal transaksi debet atau kredit yang ada pada jurnal umum. From jurnal dibuat dengan menggunakan fungsi =SUMIF(JU_KODE;B10;JU_DEBET)-SUMIF(JU_KODE;B10;JU_KREDIT).

4. Kolom jumlah berfungsi untuk melihat posisi jumlah aset, kewajiban, dan modal pada usaha yang dijalankan, dibuat dengan menggunakan fungsi $=\mathrm{IF}(\mathrm{I} 10=" \mathrm{D} "$;G10+D10-H10;H10+D10-G10). 


\section{Simpulan dan Saran}

Berdasarkan hasil penelitian pada Sunshine Laundry mengenai desain laporan keuangan dengan menggunakan miscrosoft excel, dapat disimpulkan hal-hal berikut. Pertama, sistem pencatatan laporan keuangan pada Sunshine Laundry masih dilakukan secara manual tanpa menggunakan aplikasi, sehingga proses pencatatan akuntansi belum sesuai dengan SAK EMKM. Kedua, laporan keuangan pada Sunshine Laundry dirancang dengan menggunakan Microsoft Excel 2013. Rancangan laporan keuangan dengan menggunakan aplikasi dibantu dengan data flow diagram untuk menggambarkan alur sistem yang terdiri dari sheet rancangan menu, modul 1, modul 2, daftar harga, daftar transaksi, tipe akun, chart of account, jurnal umum, laporan laba rugi, dan laporan posisi keuangan. berikut :

Berdasarkan kesimpulan diatas, maka saran yang diusulkan oleh peneliti sebagai

Pertama, hasil penelitian ini dapat digunakan oleh Sunshine Laundry untuk memperbaiki sistem pencatatan keuangan usaha, sehingga pemilik usaha dapat mengetahui keuntungan atau kerugian yang dihasilkan oleh usaha dalam suatu periode akuntansi.

Kedua, penelitian selanjutnya, diharapkan dapat mengembangkan aplikasi ini dengan menggunakan VBA Macro pada rancangan laporan keuangan yang berdasarkan standar akuntansi entitas mikro, kecil, dan menengah.

\section{Daftar Pustaka}

Aditya, R., \& Wardhana, A. (2016). Pengaruh perceived usefulness dan perceived ease of use terhadap behavioral intention dengan pendekatan Technology Acceptance Model (TAM) pada pengguna Instant Messaging LINE di Indonesia. Jurnal Siasat Bisnis, 20(1), 24-32. https://doi.org/10.20885/jsb.vol20.iss1.art3

Andarsari, P. R., \& Dura, J. (2018). IMPLEMENTASI PENCATATAN KEUANGAN PADA USAHA KECIL DAN MENENGAH. Jurnal Ilmiah Bisnis Dan Ekonomi Asia. https://doi.org/10.32812/jibeka.v12i1.16

Bedard, J. C., Jackson, C., Ettredge, M. L., \& Johnstone, K. M. (2003). The effect of training on auditors' acceptance of an electronic work system. International Journal of Accounting Information Systems, 4(4), 227-250.

https://doi.org/10.1016/j.accinf.2003.05.001

Carey, P. (2015). External Accountants' Busi- ness Advice and SME Performance. Pacific Accounting Review, 27(2). https://doi.org/10.1108/PAR-04- 2013-0020

Coram, P. J. (2018). Discussion of: Accounting practitioners' attitudes toward accounting harmonization: Adoption of ifrs for smes in italy. Journal of International Accounting Research. https://doi.org/10.2308/jiar-10630

Darmaningtyas, I. G. B., \& Suardana, K. A. (2017). Pengaruh Technology Acceptance Model (TAM) dalam Penggunaan Software oleh Auditor yang Berimplikasi pada Kinerja Auditor. E-Jurnal Akuntansi, 21, 2448-2478. https://doi.org/10.24843/EJA.2017.v21.i03.p27 
Daspit, J. J., \& D’Souza, D. E. (2017). Capability Configuration in Software Industry SMEs: The CAO Model of Ordinary Capabilities. In Journal of Small Business Management. https://doi.org/10.1111/jsbm.12330

Hasan, A., \& Gusnardi. (2018). Prospek Implementasi Standar Akuntansi : Entitas Mikro, Kecil, dan Menengah Berbasis Kualitas Laporan Keuangan yang Berlaku Efektif per 1 Januari 2018. The Sadari Institute (SADARIPRESS).

Indriantoro, N., \& Supomo, B. (2016). Metode Penelitian Bisnis untuk Akuntansi \& Manajemen. In EKONOMI.

Kim, H. D., Lee, I., \& Lee, C. K. (2013). Building Web 2.0 enterprises: A study of small and medium enterprises in the United States. In International Small Business Journal. https://doi.org/10.1177/0266242611409785

Kim, S. H., Jang, S. Y., \& Yang, K. H. (2017). Analysis of the Determinants of Softwareas-a-Service Adoption in Small Businesses: Risks, Benefits, and Organizational and Environmental Factors. Journal of Small Business Management. https://doi.org/10.1111/jsbm.12304

Kurniawati, H. A., Arif, A., \& Winarno, W. A. (2017). Analisis Minat Penggunaan Mobile Banking Dengan Pendekatan Technology Acceptance Model (TAM) Yang Telah Dimodifikasi. E-Journal Ekonomi Bisnis Dan Akuntansi, 4(1), 24. https://doi.org/10.19184/ejeba.v4i1.4563

Mulyadi. (2016). Sistem Akuntansi (Cetakan Em). Salemba Empat.

Murtiningtyas, T. (2013). Survei Pemahaman dan Kepatuhan Wajib Pajak (Studi pada UKM di Kelurahan Blimbing dan Lowokwaru Malang). The 6th NCFB and Doctoral Colloquium Unika Widya Mandala Surabaya.

Nicholas, C., \& Fruhmann, M. (2014). Small and Medium-Sized Enterprises Policies in Public Procurement: Time for a Rethink? Journal of Public Procurement, 14(3), 328-360. https://doi.org/10.1108/JOPP-14-03-2014-B002

Pantow, A. K., Sungkowo, B., Limpeleh, E. A. N., \& Tand, A. A. (2021). Penerimaan Mahasiswa Akuntansi atas Aplikasi Myob Accounting dengan Pendekatan Technology Acceptance Model. Owner, 5(1). https://doi.org/10.33395/owner.v5i1.314

Rahmawati, R. N., \& Narsa, I. M. (2019). Intention to Use e-Learning: Aplikasi Technology Acceptance Model (TAM). Owner, 3(2), 260. https://doi.org/10.33395/owner.v3i2.151

Sari, D. P. (2013). Telisik Perlakuan Teori Entitas dalam Usaha Mikro, Kecil dan Menengah (UMKM). Jurnal Akuntansi Multiparadigma. https://doi.org/10.18202/jamal.2013.08.7192

Wang, Y. S. (2002). The adoption of electronic tax filing systems: An empirical study. Government Information Quarterly, 20, 333-352. https://doi.org/10.1016/j.giq.2003.08.005 
Wicaksono, S. R., Suryana, T., \& Koesheryatin. (2008). Mengenal Microsoft Office 2013 (Indonesian Edition) (Indonesian). Gematika Jurnal Manajemen Informatika, 2013(2).

Xie, Y., Allen, C. J., \& Ali, M. (2014). An integrated decision support system for ERP implementation in small and medium sized enterprises. Journal of Enterprise Information Management. https://doi.org/10.1108/JEIM-10-2012-0077 